\title{
Salivary gland-type lung carcinomas: an EGFR immunohistochemical, molecular genetic, and mutational analysis study
}

\author{
Ricardo S Macarenco ${ }^{1}$, Timothy S Uphoff ${ }^{2}$, Heather Flynn Gilmer ${ }^{3}$, Robert B Jenkins ${ }^{3}$, \\ Stephen N Thibodeau ${ }^{4}$, Jean E Lewis ${ }^{5}$, Julian R Molina ${ }^{6}$, Ping Yang ${ }^{7}$ and \\ Marie-Christine Aubry
}

${ }^{1}$ CIPAX, Medicina Diagnostica, Sao Jose dos Campos, São Paulo, Brazil; ${ }^{2}$ Molecular Pathology, Marshfield Clinic, Marshfield, WI, USA; ${ }^{3}$ Department of Laboratory Medicine and Pathology, Division of Cytogenetics, Mayo Clinic, Rochester, MN, USA ; ${ }^{4}$ Department of Laboratory Medicine and Pathology, Division of Molecular Genetics, Mayo Clinic, Rochester, MN, USA; ${ }^{5}$ Department of Laboratory Medicine and Pathology, Division of Anatomic Pathology, Mayo Clinic, Rochester, MN, USA; ${ }^{6}$ Department of Oncology, Division of Medical Oncology, Mayo Clinic, Rochester, MN, USA and ${ }^{7}$ Department of Health Science Research, Division of Epidemiology, Mayo Clinic, Rochester, MN, USA

\begin{abstract}
Salivary gland-type lung carcinomas are uncommon neoplasms of the lung, the two most common being adenoid cystic carcinoma and mucoepidermoid carcinoma. Although they usually have an indolent behavior, adenoid cystic carcinomas can be more aggressive, with $\mathbf{5 - y e a r}$ survival as low as $55 \%$. Unfortunately, these tumors do not respond well to chemotherapy. In contrast to the most common subtypes of lung carcinomas, epidermal growth factor receptor studies have not been carried out in this group of tumors. Herein we report a series of 24 cases (12 adenoid cystic and 12 mucoepidermoid carcinomas) tested for epidermal growth factor receptor protein expression, epidermal growth factor receptor gene copy gains, and epidermal growth factor receptor gene mutational status, through immunohistochemistry, fluorescence in situ hybridization, and sequencing of the exons 18-21, respectively. Overall, 91 and $92 \%$ of the adenoid cystic carcinomas and mucoepidermoid carcinomas expressed epidermal growth factor receptor protein. Chromosome 7 polysomy occurred in $25 \%$ of the cases (four adenoid cystic carcinomas and two mucoepidermoid carcinomas). No epidermal growth factor receptor gene amplification was detected and no mutation was found in exons 18-21 of the epidermal growth factor receptor gene. Immunoexpression of epidermal growth factor receptor in salivary gland-type lung carcinomas is not related to epidermal growth factor receptor gene copy number or mutational status.
\end{abstract}

Modern Pathology (2008) 21, 1168-1175; doi:10.1038/modpathol.2008.113; published online 27 June 2008

Keywords: salivary gland-type lung carcinoma; adenoid cystic carcinoma; mucoepidermoid carcinoma; epidermal growth factor receptor; immunohistochemistry; FISH

Salivary gland-type lung carcinomas are uncommon, representing less than $1 \%$ of all lung tumors. Adenoid cystic carcinoma and mucoepidermoid carcinoma are the two most common subtypes. ${ }^{1,2}$ Salivary gland-type lung carcinomas are generally reported as having a good prognosis. Indeed, mucoepidermoid carcinoma usually presents as a localized disease that can be completely resected

Correspondence: Dr M-C Aubry, MD, Department of Laboratory Medicine and Pathology, Division of Anatomic Pathology, Mayo Clinic, 200 First Street SW, Rochester, MN 55905, USA.

E-mail: aubry.mariechristine@mayo.edu

Received 11 March 2008; revised 22 May 2008; accepted 23 May 2008; published online 27 June 2008 with surgery and the reported 5- and 10-year survivals rates are both $87 \% .^{3}$ However, patients with mucoepidermoid carcinomas can develop local or distant metastasis, which are typically unresponsive to conventional chemotherapy and radiation. In contrast, adenoid cystic carcinoma tends to present at a higher stage, is often unresectable, or, if resected, often has positive margins and subsequent local recurrences. The prognosis is also poorer with recent reported 5- and 10-year survivals of 55 and $39 \%$, respectively. ${ }^{3}$ As with mucoepidermoid carcinoma, the survival does not appear to be affected by traditional chemotherapy and radiation. Therefore, there appears to be a potential use for targeted novel therapies in the care of these patients. 
Epidermal growth factor receptor (EGFR) is a $170 \mathrm{kDa}$ transmembrane glycoprotein composed of an extracellular ligand-binding domain, a hydrophobic region, and a cytoplasmic region that contains the tyrosine-kinase domain. Binding of ligands to the receptor activates the $\mathrm{P} 13 \mathrm{k} / \mathrm{AKT}$ and RAS/ RAF/MAPK signaling pathways that are important in the regulation of cellular processes such as proliferation and apoptosis., ${ }^{4,5}$ EGFR is commonly overexpressed in lung cancer ${ }^{6}$ and several clinical trials have studied the efficacy of EGFR tyrosinekinase inhibitors, including erlotinib and gefitinib, in relapsed advanced non-small-cell lung carcinomas. The overall response rate is approximately $10 \%$ with a small subset of patients composed of women, nonsmoker, mainly Asian, with adenocarcinomas showing the most significant responses. Further research has been directed toward understanding the correlation between tumor response to EGFR tyrosine-kinase inhibitors and the biology of EGFR. There appears to be a strong correlation between EGFR gene somatic mutations in the tyrosine-kinase encoding exons (18-21) of nonsmall-cell lung carcinomas, predominantly adenocarcinomas, and tumor response., ${ }^{7,8}$ However, amplification of EGFR by fluorescent in situ hybridization (FISH) was not only associated with tumor response but also overall survival. ${ }^{9}$ Although expression of EGFR detected by immunohistochemistry is common, it does not appear to correlate with tumor response but may be useful as a screening test. Consequently, more studies are underway to establish the useful role of genetic tests as predictors of responsiveness to tyrosine-kinase inhibitors. ${ }^{10}$

EGFR mutations ${ }^{11}$ and amplification/polysomy ${ }^{12}$ have been reported in adenocarcinomas of the lung. Neuroendocrine tumors of the lung, including small cell carcinomas, usually do not express EGFR ${ }^{13}$ and are virtually always negative for EGFR mutation. ${ }^{14}$ Although EGFR expression has been reported in salivary gland carcinomas of the head and neck, ${ }^{15-18}$ little is known about EGFR mutation, amplification, and expression in salivary gland-type tumors of the lung.

The aims of the present study were to evaluate the mutational status of the exons 18, 19, 20, and 21 of the EGFR gene, the occurrence of EGFR amplification, and the EGFR expression in adenoid cystic carcinomas and mucoepidermoid carcinomas of the lung.

\section{Materials and methods}

This study was conducted after Mayo Foundation Institutional Review Board approval. Between 1972 and 2002, 62 salivary gland-type lung carcinomas were identified in the Mayo Clinic, Rochester records and detailed results published. ${ }^{3}$ Of these cases, 24 (12 adenoid cystic carcinomas and 12 mucoepidermoid carcinomas) were selected for this study, based on the availability of specimens from surgical resections or large biopsy specimens and quality of tissue.

\section{Immunohistochemical Study}

Immunohistochemical stains were performed on representative $4 \mu \mathrm{m}$ formalin-fixed, paraffin-embedded tissue sections from the specimens using an EGFR kit with prediluted mouse monoclonal antibody 2-18C9 (Dako, Carpinteria, CA, USA) according to the manufacturer's instruction. Immunostaining was performed using the PharmD X platform with the Dako Autostainer (Dako). Appropriate positive and negative controls were employed. Positive results were defined as $>1 \%$ tumor cells showing membranous staining of any intensity. The percentage of positive cells and intensity, defined as mild $1+$, moderate $2+$, and strong $3+$, were recorded for each case. In one adenoid cystic carcinoma case, the immunohistochemistry was not performed because of limited amount of tissue remaining in the paraffin block.

\section{Fluorescent In Situ Hybridization}

FISH interphase analysis of EGFR amplification was performed by using the standard method with the dual-color EGFR SpectrumOrange/CEP7 SpectrumGreen probe and paraffin pretreatment reagent kit (Vysis, Downers Grove, IL, USA). ${ }^{19}$ Briefly, interphase FISH studies were performed on paraffin-embedded tissue. Tissue sections $(4 \mu \mathrm{m})$ were initially deparaffinized in xylene $(2 \times 15 \mathrm{~min})$, dehydrated twice in $100 \%$ in ethanol for $5 \mathrm{~min}$, and treated with $10 \mathrm{mmol} / \mathrm{l}$ citric acid for $10 \mathrm{~min}$ in a humid microwave. The tissue sections were then transferred to $37^{\circ} \mathrm{C}, 2 \times \mathrm{SSC}$ for $5 \mathrm{~min}$ and protein digested with Digest All-3 (Zymed, San Francisco, CA, USA). After brief washing in $1 \times$ PBS, the slides were sequentially dehydrated in alcohol $(70,85$, and $100 \%$ ) and air-dried at room temperature. The sections were denatured at $80^{\circ} \mathrm{C}$ for $5 \mathrm{~min}$ and probe hybridization was carried out overnight in a humidified chamber at $37^{\circ} \mathrm{C}$. The sections were then washed in $0.1 \% \mathrm{NP} 40 / 2 \times \mathrm{SSC}$ at $76^{\circ} \mathrm{C}$ for $4 \mathrm{~min}$, then washed in $0.1 \% \mathrm{NP} 40 / 2 \times \mathrm{SSC}$ at room temperature for $1 \mathrm{~min}$. Slides were then mounted in Vactashield mounting medium with $1.5 \mu \mathrm{g} / \mathrm{ml}$ of 40,6-diamidino-2-phenylindole. The histological areas previously selected on the $\mathrm{H} \& \mathrm{E}$ stained sections were identified on the FISH-treated slides. Only individual and well-delineated cells were scored. Overlapping cells were excluded from the analysis. At least 60 cells were scored for each case. Each tumor was assessed by the average and the maximum numbers of copies of EGFR genes per cell and the average EGFR/chromosome 7 copy number (CEP7) ratio. Amplification was defined as a ratio of EGFR signals to chromosome 7 centromere signals of 
2.0 or more. Chromosome 7 polysomy was defined as greater than $30 \%$ nuclei with three or more CEP7 signals. Similar criteria have been used for previous studies of HER2 amplification/polysomy in breast cancer. $^{20}$

\section{EGFR Tyrosine-Kinase Domain Sequencing}

Mutational analysis studies were performed in all cases according to a previously reported protocol. ${ }^{7}$ Genomic DNA was isolated from primary tumor samples by overnight digestion with sodium dodecyl sulfate and proteinase $\mathrm{K}$ (Life Technologies Inc., Rockville, MD, USA) at $37^{\circ} \mathrm{C}$, followed by standard phenol-chloroform $(1: 1, \mathrm{v} / \mathrm{v})$ extraction and ethanol precipitation. Intron-based polymerase chain reaction (PCR) primers were used to amplify exons 18, 19, 20, and 21, which comprise the tyrosine-kinase domain of the EGFR gene. The primers were as follows (forward and reverse, respectively): exon 18 (5'-AGCATGGTGAGGGCTGAGGTGAC- $3^{\prime}$ and $5^{\prime}$-AT ATACAGCTTGCAAGGACTCTGG-3'), exon 19 (5' CCAGATCACTGGGCAGCATGTGGCACC- $3^{\prime}$ and $5^{\prime}$ AGCAGGGTCTAGAGCAGAGCAGCTGCC-3'), exon 20 (5'-GATCGCATTCATGCGTCTTCACC- $3^{\prime}$ and $5^{\prime}$-TTG CTATCCCAGGAGCGCAGACC-3'), exon 21 (5'-TCA GAGCCTGGCATGAACATGACCCTG-3' and $5^{\prime}$-GGT CCCTGGTGTCAGGAAAATGCTGG- $3^{\prime}$ ). All PCR assays were carried out in a $25 \mu \mathrm{l}$ reaction volume that contained $100 \mathrm{ng}$ of genomic DNA and 1.25 units of HotStarTaq DNA polymerase (Qiagen Inc.,
Valencia, CA, USA). DNA was amplified for 33 cycles at $95^{\circ} \mathrm{C}$ for $30 \mathrm{~s}, 65^{\circ} \mathrm{C}$ for $30 \mathrm{~s}$, and $72^{\circ} \mathrm{C}$ for $45 \mathrm{~s}$, followed by a 7 -min extension at $72^{\circ} \mathrm{C}$. All PCR products were incubated with exonuclease I and shrimp alkaline phosphatase (Amersham Biosciences Corp., Piscataway, NJ, USA) according to the manufacturer's instructions and then sequenced directly using the Applied Biosystems PRISM dye terminator cycle sequencing method (PerkinElmer Corp., Foster City, CA, USA). All sequence variants were confirmed by sequencing the products of independent PCR amplifications in both directions.

\section{Results}

\section{Clinicopathological Findings}

There were 13 women (54\%) and 11 men (46\%) with an average age of 46 years (Table 1). The majority of adenoid cystic carcinoma cases were cribriform (nine cases, $75 \%$ ) with rare solid grade three (two cases, 17\%), and tubular grade 1 (one case, $8 \%$ ) types. Seven (58\%) mucoepidermoid cases were grade 2 and five (42\%) cases were grade 1 .

\section{Immunohistochemical Study}

Immunohistochemical studies were performed in 11 adenoid cystic carcinoma cases and in 12 mucoepidermoid cases and results are presented in Table 2. Overall EGFR expression was detected in 21 cases

Table 1 Clinicopathological features of patients with salivary gland-type lung carcinoma

\begin{tabular}{|c|c|c|c|c|c|c|c|c|}
\hline Case number & Age & Size & Histologic type & Grade & $L N 1$ & LN2 & Local recurrence & Metastasis \\
\hline 1 & 21 & 4.5 & ACC & 3 & - & - & - & Liver \\
\hline 2 & 36 & 5.5 & ACC & 2 & - & - & - & - \\
\hline 3 & 46 & 5.1 & ACC & 1 & - & - & - & - \\
\hline 4 & 47 & 2.8 & ACC & 2 & - & + & + & Brain/lung/bone \\
\hline 5 & 48 & 3.3 & ACC & 2 & + & - & - & - \\
\hline 6 & 51 & 4 & ACC & 2 & + & - & - & - \\
\hline 7 & 57 & NA & ACC & 2 & - & + & + & Lung \\
\hline 8 & 59 & 1.3 & ACC & 2 & - & + & - & Lung \\
\hline 9 & 61 & $>1.8$ & ACC & 2 & - & + & + & - \\
\hline 10 & 63 & NA & ACC & 2 & - & + & - & - \\
\hline 11 & 66 & 1.8 & ACC & 3 & - & - & - & - \\
\hline 12 & 76 & 2 & ACC & 2 & - & - & - & - \\
\hline 13 & 18 & 2.4 & MEC & 1 & - & - & - & - \\
\hline 14 & 21 & 2 & MEC & 2 & - & - & - & - \\
\hline 15 & 24 & 2 & MEC & 1 & - & - & - & - \\
\hline 16 & 28 & 2 & MEC & 1 & - & - & - & - \\
\hline 17 & 36 & 1.2 & MEC & 1 & - & - & - & - \\
\hline 18 & 40 & 1.5 & MEC & 2 & - & - & - & - \\
\hline 19 & 40 & 1.8 & MEC & 1 & - & - & - & - \\
\hline 20 & 41 & 1.6 & MEC & 2 & - & - & - & - \\
\hline 21 & 47 & 3.5 & MEC & 2 & - & - & - & - \\
\hline 22 & 61 & 3.3 & MEC & 2 & + & - & - & Bone \\
\hline 23 & 63 & 4.5 & MEC & 2 & - & - & - & - \\
\hline 24 & 65 & 0.9 & MEC & 2 & - & + & - & - \\
\hline
\end{tabular}

ACC, adenoid cystic carcinoma; MEC, mucoepidermoid carcinoma; NA, not assessable; LN1, metastasis in ipsilateral peribronchial and/or ipsilateral hilar lymph nodes, including intrapulmonary nodes involved by direct extension of the primary tumor lymph node metastasis; LN2, metastasis in ipsilateral mediastinal and/or subcarinal lymph node(s). 
Table 2 Results of EGFR expression, EGFR amplification, and EGFR mutation in salivary gland-type lung tumors

\begin{tabular}{|c|c|c|c|c|c|}
\hline Case & Histology & EGFR IHC \% of + cells & EGFR IHC intensity & EGFR amplification & EGFR mutation \\
\hline 1 & ACC/grade 3 & 20 & Strong & Normal & - \\
\hline 2 & ACC/grade 2 & 10 & Moderate & $7+$ & - \\
\hline 3 & ACC/grade 1 & 30 & Moderate & Normal & - \\
\hline 4 & ACC/grade 2 & 90 & Strong & Normal & - \\
\hline 5 & ACC/grade 2 & 40 & Moderate & Normal & - \\
\hline 6 & ACC/grade 2 & 40 & Moderate & $7+$ & - \\
\hline 7 & ACC/grade 2 & NA & NA & Normal & - \\
\hline 8 & ACC/grade 2 & 70 & Moderate & Normal & - \\
\hline 9 & ACC/grade 2 & 50 & Moderate & Normal & - \\
\hline 10 & ACC/grade 2 & 0 & 0 & $7+$ & - \\
\hline 11 & ACC/grade 3 & 15 & Moderate & $7+$ & - \\
\hline 12 & ACC/grade 2 & 30 & Moderate & Normal & - \\
\hline 13 & MEC/grade 1 & 50 & Strong & $7+$ & - \\
\hline 14 & MEC/grade 2 & 10 & Strong & Normal & - \\
\hline 15 & MEC/grade 1 & 20 & Moderate & Normal & - \\
\hline 16 & MEC/grade 1 & 30 & Moderate & Normal & - \\
\hline 17 & MEC/grade 1 & 50 & Strong & Normal & - \\
\hline 18 & MEC/grade 2 & 70 & Strong & Normal & - \\
\hline 19 & MEC/grade 1 & 40 & Strong & Normal & - \\
\hline 20 & MEC/grade 2 & 30 & Moderate & Normal & - \\
\hline 21 & MEC/grade 2 & 40 & Moderate & Normal & - \\
\hline 22 & MEC/grade 2 & 10 & Strong & Normal & - \\
\hline 23 & MEC/grade 2 & $<5$ & Strong & $7+$ & - \\
\hline 24 & MEC/grade 2 & 0 & 0 & Normal & - \\
\hline
\end{tabular}

ACC, adenoid cystic carcinoma; MEC, mucoepidermoid carcinoma; EGFR, epidermal growth factor receptor; NA, not assessable; 7+, chromosome 7 polysomy.
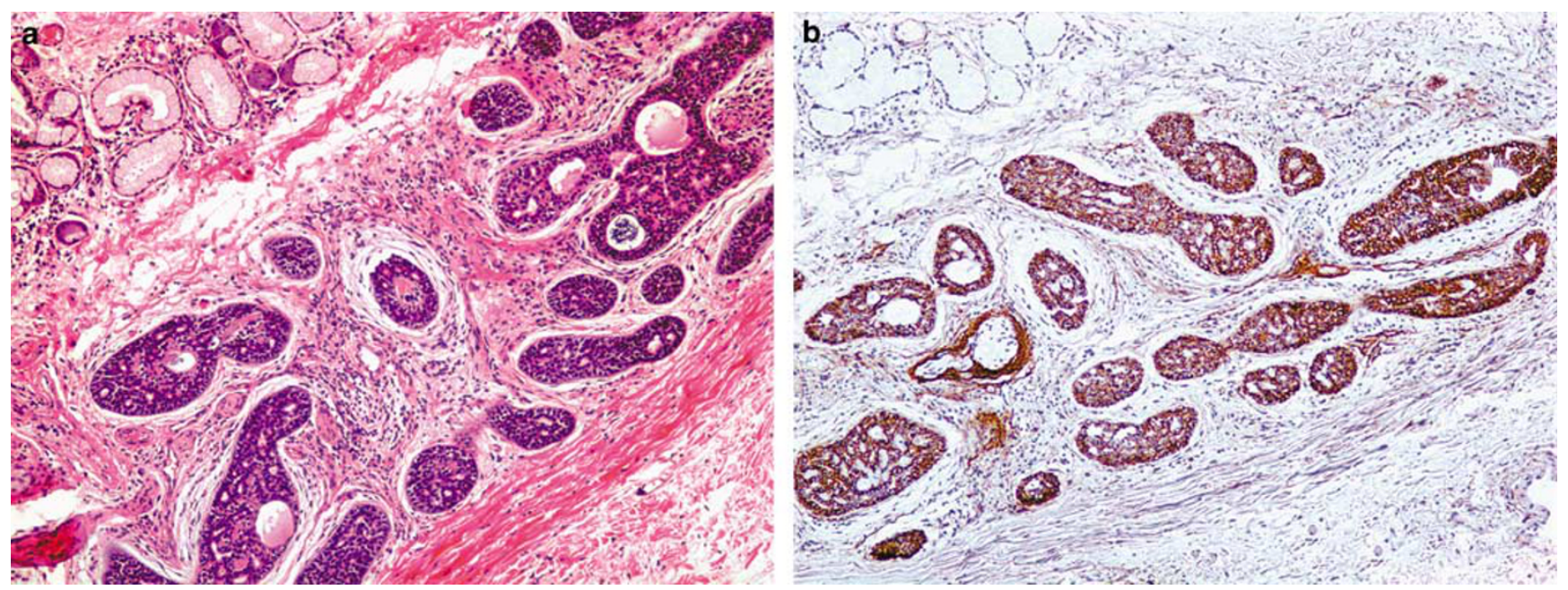

Figure 1 Intermediate power photomicrograph of a grade 2 adenoid cystic carcinoma showing diffuse expression of EGFR ((a) H\&E, $\times 200$; (b) EGFR, $\times 100)$.

(91\%), specifically in $10(91 \%)$ adenoid cystic carcinoma, and in $11(92 \%)$ mucoepidermoid carcinomas. In average, EGFR was expressed in 40 (range: $10-90 \%$ ) and $35 \%$ (range: $5-70 \%$ ) of cells in adenoid cystic carcinomas and mucoepidermoid carcinomas positive cases, respectively (Figure 1). The intensity of staining was usually moderate to strong in both tumor types. Expression of EGFR was not uniform in the tumors. Indeed, EGFR was often expressed in the cells at the periphery of nests tumor cells in adenoid cystic carcinomas. In mucoepidermoid carcinomas, EGFR was strongly expressed in squamous and intermediate cells and goblet cells usually were negative (Figure 2).

\section{Fluorescence In Situ Hybridization}

FISH analysis results are summarized in the Table 2. There was no amplification of the EGFR gene in any case. Polysomy of chromosome 7 occurred in six $(25 \%)$ cases, two mucoepidermoid carcinomas $(17 \%)$ and four adenoid cystic carcinomas (33\%) (Figure 3). Patients with tumors harboring polysomy 7 

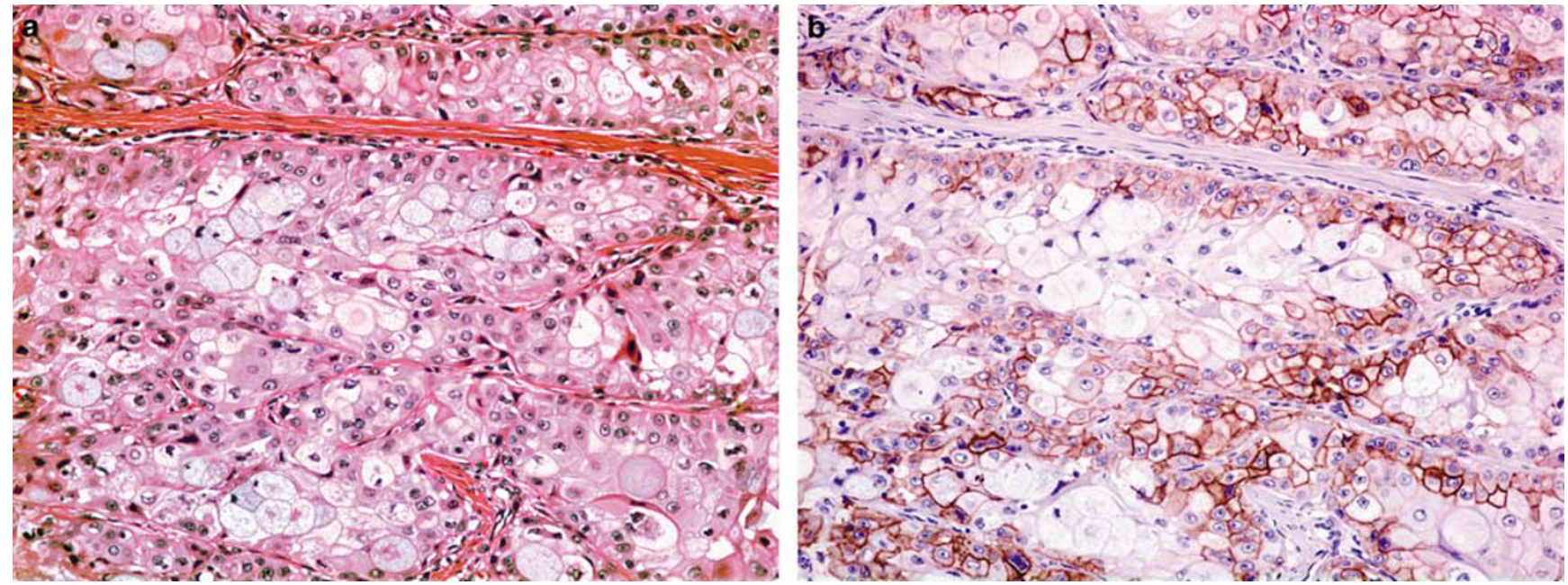

Figure 2 Intermediate power photomicrograph of a grade 2 mucoepidermoid carcinoma ((a) H\&E, $\times 200)$. The expression of EGFR is seen mainly in the squamous and intermediate cells with sparing of goblet cells ((b) EGFR, $\times 200)$.
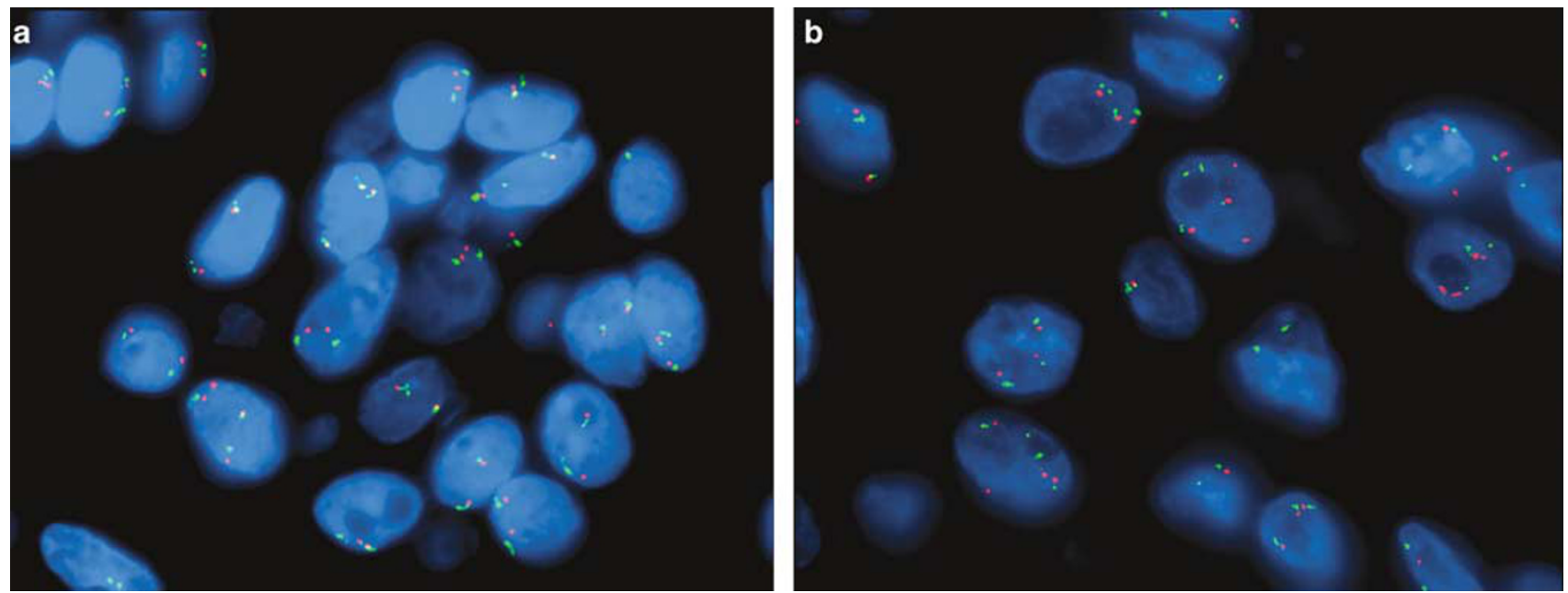

Figure 3 FISH for EGFR did not show amplification and was normal in the majority of cases ((a) EGFR=red probe and centromere 7 =green probe). A small subset of salivary gland-type tumors showed polysomy of chromosome 7 (b).

Table 3 Clinical features of chromosome 7 polysomic cases and chromosome 7 non-polysomic cases

\begin{tabular}{lccc}
\hline & $\begin{array}{c}\text { Polysomy } 7 \\
(\mathrm{n}=6)\end{array}$ & $\begin{array}{c}\text { No polysomy } \\
7 \text { (n=18) }\end{array}$ & P-value \\
\hline Gender F/M & $4 / 2$ & $9 / 9$ & $0.65^{*}$ \\
Age (mean, years) & 50 & 45 & \\
Smoker/nonsmoker & $2 / 4$ & $8 / 10$ & $1.00^{*}$ \\
Tumor size (mean, cm) & 3,6 & 2,4 & \\
Tumor grade, N: grade & $1 / 4 / 1$ & $5 / 12 / 1$ & $0.64^{* *}$ \\
$\begin{array}{l}\text { 1/grade 2/grade 3 } \\
\text { Wall infiltration, N (\%) }\end{array}$ & $5(83)$ & $9(53)$ & \\
Lymph node metastasis, & $2(33)$ & $7(39)$ & $0.28^{*}$ \\
N (\%) & & $5(28)$ & \\
Distant metastasis, N (\%) & $0(0)$ & 5 & \\
\hline
\end{tabular}

F, female; M, male.

${ }^{*} P$ not significant through Fisher's exact test; ${ }^{*} P$ not significant through $\chi^{2}$-test. tended to be nonsmoking women (Table 3). The tumors were larger and more infiltrative. Lymph node and distant metastasis were less common in this group, although results were not statistically significant.

\section{EGFR Tyrosine-Kinase Domain Sequencing}

The sequencing studies revealed no mutations in the sequences from the exons 18, 19, 20, and 21 of the EGFR gene in all cases (Table 2).

\section{Discussion}

Our results show that although EGFR expression in salivary gland-type lung carcinomas is common, it is 
not associated with amplification or mutation within the tyrosine-kinase domain of the EGFR gene. Compared to other lung neoplasms, EGFR expression occurs more frequently in salivary gland-type tumors. Indeed, EGFR is expressed in about $80 \%$ of squamous cell carcinomas, ${ }^{21} 50 \%$ of lung adenocarcinomas, ${ }^{21}$ and in less than $5 \%$ of the neuroendocrine carcinomas, ${ }^{13}$ whereas it was expressed in more than $90 \%$ of the cases in our series. Some studies have suggested that the mechanisms of EGFR protein overexpression vary depending on tumor type. For example, gene amplification has been implicated as a major cause of EGFR protein expression in glioblastomas, ${ }^{22}$ esophageal squamous cell carcinoma, ${ }^{23}$ and colon carcinoma, ${ }^{24}$ whereas the relationship between EGFR protein expression and gene amplification or mutation is not clearly understood in lung carcinoma. Some studies observed that somatic mutations of EGFR tyrosinekinase domain of non-small-cell lung carcinomas were associated with immunoexpression, ${ }^{6}$ while other studies have shown that overexpression of EGFR was better associated with EGFR amplification or polysomy. ${ }^{21}$ To our knowledge, this issue has not been explored in salivary gland-type tumors of the lung. Our study demonstrates that EGFR amplification and somatic mutation of the tyrosine-kinase domain of EGFR gene are not required for protein expression, and suggests that other mechanisms such as transcriptional or posttranscriptional events are involved in EGFR expression in these tumors.

In contrast to other subtypes of non-small-cell lung carcinomas, salivary gland-type tumors do not harbor mutation of the EGFR tyrosine-kinase domain. ${ }^{11,14}$ Indeed, approximately $6-37 \%$ of adenocarcinomas $^{8,25,26}$ and $22-64 \%$ of bronchioloalveolar carcinomas $^{11,25,26}$ have EGFR mutations. Although the number of cases in our study is small, compared to larger series of non-small-cell lung carcinoma, given the rarity of salivary gland-type lung carcinomas, our data strongly suggest that EGFR tyrosinekinase domain mutation is unlikely to occur in these tumors. Whether ethnic factors may influence the EGFR mutational status in these tumors is a subject for further investigations.

Similarly, EGFR gene amplification has been identified in about 9-11\% of non-small-cell lung carcinomas. ${ }^{27-29}$ Although no amplification of EGFR was identified, copy gains of EGFR gene occurred in a quarter of our cases secondarily to polysomy of chromosome 7 . This alteration was twice as common in adenoid cystic carcinomas compared to mucoepidermoid carcinomas. Although abnormalities of chromosome 7 have been described in mucoepidermoid carcinomas of salivary glands, this is not well recognized in adenoid cystic carcinomas as well as salivary gland-type carcinomas of the lung. Indeed, classical cytogenetics data on mucoepidermoid carcinomas of salivary glands show that a subset of cases harbor polysomy of multiple chromosomes including the chromosome 7 , whereas most cases harbor other chromosomal alterations, including the typical translocation $t(11 ; 19)(q 14-$ 21;p12) without involvement of the chromosome $7 .^{30}$ A karyotype on mucoepidermoid carcinoma of the bronchial tree did not show any alteration of chromosome $7,{ }^{31}$ however, recently, a comparative genomic hybridization study found partial gain within the short arm of chromosome 7 in cell lines derived from salivary gland and bronchial mucoepidermoid carcinomas. ${ }^{32}$ Furthermore, among several molecular studies performed on adenoid cystic carcinomas from other organs, ${ }^{33-37}$ only one recent study found recurrent gains of $7 \mathrm{p} 15.2$ in salivary gland and bronchial adenoid cystic carcinomas using comparative genomic hybridization. ${ }^{38} \mathrm{~A}$ previous cytogenetic study on an adenoid cystic carcinoma of the respiratory tree did not reveal any alteration in the chromosome 7 , instead translocations $t(X ; 6)$ and $t(9 ; 17)$ were the main aberrations detected. ${ }^{39}$ Therefore, our results support that polysomy of chromosome 7 is not uncommon in salivary gland-type carcinomas of the lung and had thus far not been well recognized.

The significance of chromosome 7 polysomy remains to be further investigated. Although recognized in the tumorigenesis of non-small-cell lung carcinoma, only rare studies have suggested a prognostic role. Indeed, although one study reported no significant prognostic value, ${ }^{40}$ increased EGFR gene and chromosome 7 copy numbers were reportedly associated with poor tumor differentiation but were less frequent in $\mathrm{T} 4$ compared to $\mathrm{T} 1$ tumors. ${ }^{28}$ Also, increased EGFR gene and chromosome 7 copy numbers tended to be less frequent in tumors with lymph node metastasis. ${ }^{28}$ These results would suggest that chromosome 7 polysomy is associated with lower stage disease, a similar finding to our study, although limited by the small number of cases. Furthermore, a recent study ${ }^{41}$ suggested that chromosome 7 polysomy was significantly associated with improved survival in a multivariate analysis of patients with non-small-cell lung carcinoma treated with gefitinib. Although EGFR gene mutation remains an important predictor of response to therapy in most studies of non-smallcell lung carcinomas, chromosome 7 polysomy may also be involved that needs further investigation.

Few studies have addressed the role of anti-EGFR treatment in head and neck salivary gland carcinomas. Experimental data suggest that concomitant inhibition of EGFR and vascular endothelial growth factor receptor tyrosine kinases reduces growth and metastasis of human salivary adenoid cystic carcinoma in a mouse model. ${ }^{42} \mathrm{~A}$ recent phase II study of lapatinib, a dual inhibitor of EGFR and HER2 activity, in recurrent or metastatic EGFR and/or HER2-expressing adenoid cystic carcinomas and other malignant tumors of the salivary glands has been conducted to evaluate its antitumoral activity. ${ }^{43}$ This study found that lapatinib probably has a cytostatic effect on carcinomas of salivary glands, 
but no objective clinical responses were detected. The relationship of EGFR expression, mutational status and copy number to therapy response has not been yet evaluated in these tumors.

In conclusion, most adenoid cystic carcinomas and mucoepidermoid carcinomas of lung express EGFR. Although no tyrosine-kinase domain mutation or amplification of EGFR was identified, chromosome 7 polysomy occurs in a considerable subset of these tumors and may have prognostic significance.

\section{Disclosure/conflict of interest}

The authors have no conflict of interest.

\section{References}

1 Yousem SA, Nicholson A. Adenoid Cystic Carcinoma Tumors of the Lung, Pleura, Thymus and Heart. IARC Press: Lyon, 2004, pp 65-66.

2 Yousem S, Nicholson A. Mucoepidermoid carcinoma. In: Travis W, Brambilla E, Muller-Hermelink H, Harris C (eds). Tumors of the Lung, Pleura, Thymus and Heart. IARC Press: Lyon, 2004, pp 63-64.

3 Molina JR, Aubry MC, Lewis JE, et al. Primary salivary gland-type lung cancer: spectrum of clinical presentation, histopathologic and prognostic factors. Cancer 2007;110:2253-2259.

4 Schlessinger J. Cell signaling by receptor tyrosine kinases. Cell 2000;103:211-225.

5 Yarden Y, Sliwkowski MX. Untangling the ErbB signalling network. Nat Rev Mol Cell Biol 2001;2: 127-137.

6 Suzuki M, Shigematsu H, Hiroshima K, et al. Epidermal growth factor receptor expression status in lung cancer correlates with its mutation. Hum Pathol 2005;36:1127-1134.

7 Lynch TJ, Bell DW, Sordella R, et al. Activating mutations in the epidermal growth factor receptor underlying responsiveness of non-small-cell lung cancer to gefitinib. N Engl J Med 2004;350:2129-2139.

8 Paez JG, Janne PA, Lee JC, et al. EGFR mutations in lung cancer: correlation with clinical response to gefitinib therapy. Science 2004;304:1497-1500.

9 Cappuzzo F, Hirsch FR, Rossi E, et al. Epidermal growth factor receptor gene and protein and gefitinib sensitivity in non-small-cell lung cancer. J Natl Cancer Inst 2005;97:643-655.

10 Dowell JE, Minna JD. EGFR mutations and molecularly targeted therapy: a new era in the treatment of lung cancer. Nat Clin Pract Oncol 2006;3:170-171.

11 Matsumoto S, Iwakawa R, Kohno T, et al. Frequent EGFR mutations in noninvasive bronchioloalveolar carcinoma. Int J Cancer 2006;118:2498-2504.

12 Hirsch FR, Varella-Garcia M, McCoy J, et al. Increased epidermal growth factor receptor gene copy number detected by fluorescence in situ hybridization associates with increased sensitivity to gefitinib in patients with bronchioloalveolar carcinoma subtypes: a Southwest Oncology Group Study. J Clin Oncol 2005;23: 6838-6845.

13 Pelosi G, Scarpa A, Veronesi G, et al. A subset of highgrade pulmonary neuroendocrine carcinomas shows up-regulation of matrix metalloproteinase-7 associated with nuclear beta-catenin immunoreactivity, independent of EGFR and HER-2 gene amplification or expression. Virchows Arch 2005;447:969-977.

14 Shigematsu H, Lin L, Takahashi T, et al. Clinical and biological features associated with epidermal growth factor receptor gene mutations in lung cancers. J Natl Cancer Inst 2005;97:339-346.

15 Yamada K, Iwai K, Okada Y, et al. Immunohistochemical expression of epidermal growth factor receptor in salivary gland tumours. Virchows Arch A Pathol Anat Histopathol 1989;415:523-531.

16 Chen CH, Li BY, Wan JT, et al. Expression of epidermal growth factor in salivary adenoid cystic carcinoma. Proc Natl Sci Counc Repub China B 2001;25:90-96.

17 Gibbons MD, Manne U, Carroll WR, et al. Molecular differences in mucoepidermoid carcinoma and adenoid cystic carcinoma of the major salivary glands. Laryngoscope 2001;111:1373-1378.

18 Mori $\mathrm{M}$, Naito R, Tsukitani $\mathrm{K}$, et al. Immunohistochemical distribution of human epidermal growth factor in salivary gland tumours. Virchows Arch A Pathol Anat Histopathol 1987;411:499-507.

19 Ionescu DN, Sasatomi E, Cieply K, et al. Protein expression and gene amplification of epidermal growth factor receptor in thymomas. Cancer 2005;103:630-636.

20 Roche PC, Suman VJ, Jenkins RB, et al. Concordance between local and central laboratory HER2 testing in the breast intergroup trial N9831. J Natl Cancer Inst 2002;94:855-857.

21 Hirsch FR, Varella-Garcia M, Bunn Jr PA, et al. Epidermal growth factor receptor in non-small-cell lung carcinomas: correlation between gene copy number and protein expression and impact on prognosis. J Clin Oncol 2003;21:3798-3807.

22 Schober R, Bilzer T, Waha A, et al. The epidermal growth factor receptor in glioblastoma: genomic amplification, protein expression, and patient survival data in a therapeutic trial. Clin Neuropathol 1995;14: 169-174.

23 Hanawa M, Suzuki S, Dobashi Y, et al. EGFR protein overexpression and gene amplification in squamous cell carcinomas of the esophagus. Int J Cancer 2006;118:1173-1180.

24 Ooi A, Takehana T, Li X, et al. Protein overexpression and gene amplification of HER-2 and EGFR in colorectal cancers: an immunohistochemical and fluorescent in situ hybridization study. Mod Pathol 2004; 17:895-904.

25 Haneda H, Sasaki H, Lindeman N, et al. A correlation between EGFR gene mutation status and bronchioloalveolar carcinoma features in Japanese patients with adenocarcinoma. Jpn J Clin Oncol 2006;36:69-75.

26 Marchetti A, Martella C, Felicioni L, et al. EGFR mutations in non-small-cell lung cancer: analysis of a large series of cases and development of a rapid and sensitive method for diagnostic screening with potential implications on pharmacologic treatment. J Clin Oncol 2005;23:857-865.

27 Hirsch FR, Varella-Garcia M, Bunn Jr PA, et al. Epidermal growth factor receptor in non-small-cell lung carcinomas: correlation between gene copy number and protein expression and impact on prognosis. J Clin Oncol 2003;21:3798-3807.

28 Dacic S, Flanagan M, Cieply K, et al. Significance of EGFR protein expression and gene amplification in 
non-small cell lung carcinoma. Am J Clin Pathol 2006;125:860-865.

29 Tsao MS, Sakurada A, Cutz JC, et al. Erlotinib in lung cancer-molecular and clinical predictors of outcome. N Engl J Med 2005;353:133-144.

30 Nordkvist A, Gustafsson H, Juberg-Ode $\mathrm{M}$, et al. Recurrent rearrangements of 11q14-22 in mucoepidermoid carcinoma. Cancer Genet Cytogenet 1994;74: 77-83.

31 Sozzi G, Miozzo M, Tagliabue E, et al. Cytogenetic abnormalities and overexpression of receptors for growth factors in normal bronchial epithelium and tumor samples of lung cancer patients. Cancer Res 1991;51:400-404.

32 Tonon G, Gehlhaus KS, Yonescu R, et al. Multiple reciprocal translocations in salivary gland mucoepidermoid carcinomas. Cancer Genet Cytogenet 2004;152:15-22.

33 El-Naggar AK, Lovell M, Callender DL, et al. Limited nonrandom chromosomal aberrations in a recurrent adenoid cystic carcinoma of the parotid gland. Cancer Genet Cytogenet 1999;109:66-69.

34 Roijer E, Dahlenfors R, Mark J, et al. Observations by chromosome banding, FISH and immunohistochemistry in an adenoid cystic carcinoma with del(17)(p13) as the sole deviation. Virchows Arch 1997;430:339-342.

35 Mark HF, Hanna I, Gnepp DR. Cytogenetic analysis of salivary gland type tumors. Oral Surg Oral Med Oral Pathol Oral Radiol Endod 1996;82:187-192.

36 Lopez-Gines C, Cerda-Nicolas M, Llombart-Bosch A. Cytogenetic findings in a new case of adenoid cystic carcinoma arising in sphenoidal sinus. Cancer Genet Cytogenet 1994;75:150-152.
37 Hrynchak M, White V, Berean K, et al. Cytogenetic findings in seven lacrimal gland neoplasms. Cancer Genet Cytogenet 1994;75:133-138.

38 Bernheim A, Toujani S, Saulnier P, et al. Highresolution array comparative genomic hybridization analysis of human bronchial and salivary adenoid cystic carcinoma. Lab Invest 2008;88:464-473.

39 Higashi K, Jin Y, Johansson M, et al. Rearrangement of 9 p13 as the primary chromosomal aberration in adenoid cystic carcinoma of the respiratory tract. Genes Chromosomes Cancer 1991;3:21-23.

40 Thatcher N, Chang A, Parikh P, et al. Gefitinib plus best supportive care in previously treated patients with refractory advanced non-small-cell lung cancer: results from a randomised, placebo-controlled, multicentre study (Iressa Survival Evaluation in Lung Cancer). Lancet 2005;366:1527-1537.

41 Buckingham LE, Coon JS, Morrison LE, et al. The prognostic value of chromosome 7 polysomy in nonsmall cell lung cancer patients treated with gefitinib. J Thorac Oncol 2007;2:414-422.

42 Younes MN, Park YW, Yazici YD, et al. Concomitant inhibition of epidermal growth factor and vascular endothelial growth factor receptor tyrosine kinases reduces growth and metastasis of human salivary adenoid cystic carcinoma in an orthotopic nude mouse model. Mol Cancer Ther 2006;5:2696-2705.

43 Agulnik M, Cohen EW, Cohen RB, et al. Phase II study of lapatinib in recurrent or metastatic epidermal growth factor receptor and/or erbB2 expressing adenoid cystic carcinoma and non adenoid cystic carcinoma malignant tumors of the salivary glands. J Clin Oncol 2007;25:3978-3984. 